\title{
Variability of the water mass transports and fluxes in the eastern North Atlantic during 2001
}

\author{
L. Barbero, ${ }^{1,2}$ M. González-Dávila, ${ }^{1}$ J. M. Santana-Casiano, ${ }^{1}$ and M. Álvarez ${ }^{3}$
}

Received 27 November 2008; revised 12 October 2009; accepted 20 October 2009; published 26 March 2010.

[1] The water mass distribution in the eastern North Atlantic Ocean $\left(39-45^{\circ} \mathrm{N}, 16-22^{\circ} \mathrm{W}\right)$ during 2001 was determined for the upper $2000 \mathrm{~m}$ within the frame of the French research program POMME, using an extended Optimum Multiparameter analysis which included both conservative and nonconservative tracers. The presence of eastern North Atlantic Central Water in its subtropical and subpolar branches, Mediterranean Water, and Labrador Sea Water was considered. The results were used in combination with mass fluxes in order to determine the transports taking place in the region and analyze the variability observed both in the direction and magnitude of the fluxes, as well as to determine the relative contribution of each water mass to the flows. The high variability of the area was evident in the changes in flux direction and magnitude; the total input into the POMME region varied from POMME 1 (3.8 Sv southward) to POMME 3 (8.8 Sv northward). Our findings, depending on the cruise considered, corroborate most of the previous and often conflicting studies in the area, both in the flow direction and magnitude, suggesting that in highly dynamic areas such as this one, estimating annual trends from individual cruises might not provide accurate descriptions of the overall transports.

Citation: Barbero, L., M. González-Dávila, J. M. Santana-Casiano, and M. Álvarez (2010), Variability of the water mass transports and fluxes in the eastern North Atlantic during 2001, J. Geophys. Res., 115, C03023, doi:10.1029/2008JC005212.

\section{Introduction}

[2] The eastern North Atlantic Ocean is known to be a major sink for carbon dioxide of anthropogenic origin. Once it enters the ocean, the entrainment and storage in the deeper layers of the ocean depend largely on the water mass transports in the area.

[3] The purpose of this paper is to carry out a study of the water mass distributions in a highly dynamic region of the North Atlantic Ocean $\left(16^{\circ}-21^{\circ} \mathrm{W}, 38^{\circ}-45^{\circ} \mathrm{N}\right)$ at different times of the year 2001, and to make an estimation of the contribution of these water masses to the mass transport, in order to study changes in direction and magnitude depending on the time of sampling. For this, we make use of the data set from the POMME project [Memery et al., 2005]. The three hydrographic surveys carried out in February, March-April, and August-September showed a quasipermanent frontal zone around $41^{\circ} \mathrm{N}-42^{\circ} \mathrm{N}$ in winter and further north (close to $43^{\circ} \mathrm{N}$ ) in summer [Memery et al., 2005; Reverdin et al., 2005]. North of $41^{\circ} \mathrm{N}$, the average mixed layer depths evolved from $150 \mathrm{~m}$ in winter to $75 \mathrm{~m}$ in spring. The area located north of the front had nutrient rich, colder, less saline waters, while waters to the south of the

\footnotetext{
${ }^{1}$ Chemistry Department and Faculty of Marine Science, University of Las Palmas de Gran Canaria, Las Palmas de Gran Canaria, Spain.

${ }^{2}$ LOCEAN, IPSL, Pierre and Marie Curie University, Paris, France.

${ }^{3}$ Instituto Mediterráneo de Estudios Avanzados, CSIC, Universitat de les Illes Balears, Esporles, Spain.
}

Copyright 2010 by the American Geophysical Union. 0148-0227/10/2008JC005212 front were poorer in nutrient content, warmer and saltier [Fernandez et al., 2005b]. The region was also characterized by the presence of a series of rather stable and well organized cyclonic and anticyclonic eddies that remained within the area during most of the year and which have been studied in detail by Fernandez et al. [2005b] and Le Cann et al. [2005].

[4] The formation and subduction of the light variety $\left(10.5^{\circ} \mathrm{C}-12^{\circ} \mathrm{C}\right)$ of Eastern North Atlantic Central Subpolar Mode Water (ENACWp [Mccartney and Talley, 1982]) dominates the subduction rates in the area. The discontinuity in the mixed layer between $40^{\circ} \mathrm{N}$ and $45^{\circ} \mathrm{N}$ has been related to the location of the Subpolar Mode Water [Memery et al., 2005 and references therein]. Paillet and Arhan [1996] stated that this water could be found in two regimes: north and south of $40^{\circ} \mathrm{N}-42^{\circ} \mathrm{N}$. In the north, ENACWp is sensitive to convection and is found between the surface and 500 $\mathrm{m}$ depth in the winter, whereas in the south, ENACWp would be isolated from the atmosphere by the appearance of a secondary pycnocline. This is the origin of a "subduction line," located near $42^{\circ} \mathrm{N}$ [e.g., Paillet, 1999].

[5] In terms of water mass distribution, the upper ocean layers in this area are bounded to the north and northwest by extensions of the North Atlantic Current (NAC) system near $51^{\circ} \mathrm{N}$, and to the south and southwest by the Azores Current (AC), near $34^{\circ} \mathrm{N}$ [Dietrich et al., 1980]. The general water mass distributions and upper circulation for the North Atlantic have been studied by numerous authors but questions remain concerning the circulation schemes in the region, as some authors pointed toward a southward [Saunders, 
Table 1. Dates on Which Each Cruise Took Place

\begin{tabular}{cc}
\hline Cruise & Dates \\
\hline POMME 1 & 3-23 February 2001 \\
POMME 2 & 28 March to 8 April 2001 \\
POMME 3 & 26 August to 13 September 2001 \\
\hline
\end{tabular}

1982; Paillet and Mercier, 1997; Gaillard et al., 2005] or westward [Pollard et al., 1996] NAC circulation. At around 1000 dbar, in the Mediterranean Water (MW) level, Saunders [1982] and Paillet and Mercier [1997] suggest a northward mean current at $\sim 41^{\circ} \mathrm{N}$, while Bower et al. [2002] found that floats launched south of $52^{\circ} \mathrm{N}$ rarely drifted northward at that depth. At the Labrador Sea Water (LSW) level, at around 1800 dbar, Speer et al. [1999] described a southwestward circulation using Lagrangian data. Le Cann et al. [2005] carried out a study of the mesoscale upper ocean circulation within the frame of the POMME project and found a mean southwestward current in the 100-500 m layer.

[6] In the paper, sections 2 and 3 describe the data set used and the method applied for the estimation of the water mass distribution in the area. In section 4 these results were combined with the geostrophic circulation schemes obtained for the area in order to estimate the water mass transports taking place. Section 5 describes the results for the transports obtained for each cruise in the upper and intermediate layers of the ocean. Section 6 summarizes the conclusions concerning the variability observed throughout 2001 .

\section{Data Set}

[7] This study used the physical and biochemical measurements determined during leg one of each of the three cruises that took place within the POMME project (Table 1). Stations were located at approximately $54 \mathrm{~km}$ intervals in latitude and longitude in order to resolve mesoscale structures (Figure 1). Samples were taken from the surface to a maximum depth of $2000 \mathrm{~m}$. During POMME 1 and POMME 2 several top to bottom stations were sampled.

[8] Profiles of physical variables, pressure, temperature and salinity were recorded with the CTD [Reverdin et al., 2005]. Discrete bottle samples for oxygen $\left(\mathrm{O}_{2}\right)$, nutrients, total alkalinity $\left(\mathrm{A}_{\mathrm{T}}\right)$ and $\mathrm{pH}$ were analyzed on board. The procedures used for analyzing the samples have been described in detail by Fernandez et al. [2005a] $\left(\mathrm{O}_{2}\right.$ and nutrients) and Gonzalez-Davila et al. [2005] ( $\mathrm{A}_{\mathrm{T}}$ and $\left.\mathrm{pH}\right)$. The total dissolved inorganic carbon $\left(\mathrm{C}_{\mathrm{T}}\right)$ was computed from $\mathrm{A}_{\mathrm{T}}-\mathrm{pH}_{\mathrm{T}}$ pairs for the water column samples [GonzalezDavila et al., 2005] using the carbonic acid dissociation constants of Mehrbach et al. [1973] after Dickson and Millero [1987].

\section{Water Mass Sources}

[9] As a general representation of the POMME region, vertical distributions of potential temperature, salinity, oxygen and normalized total dissolved inorganic carbon $\left(\mathrm{NC}_{\mathrm{T}}\right)$ during POMME 1 are shown in Figure 2. The different plots follow the border sections, starting in the southwest corner, moving north along the $20.6^{\circ} \mathrm{W}$ section, then eastward along $44.5^{\circ} \mathrm{N}$, southward along $16.6^{\circ} \mathrm{W}$ and finally returning to the starting point along $39^{\circ} \mathrm{N}$ (Figure 1). The central region of the water column, between the seasonal, and the main thermocline, is the domain of Eastern North Atlantic Central Waters [Pollard et al., 1996], where the $\theta$-S diagrams showed a linear tendency (Figure 3 ). The inset in Figure 3 shows the $\theta$-S pairs defined by cruise for temperatures higher than $10^{\circ} \mathrm{C}$, allowing the variability between cruises in these data to be observed. The salinity maximum at 900-1000 m indicated the presence of Mediterranean Water (MW) in the region and a weak minimum could be hinted at $2000 \mathrm{~m}$, as a result of the presence of Labrador Sea Water (LSW), which could also be observed in the temperature profile (Figure 2a). Oxygen behavior reflected that of salinity, with a minimum indicating the presence of MW and a weak maximum in the LSW domain. The salinity and temperature data in the southeastern corner of the box suggest the presence of a current structure, also observed through a minimum in $\mathrm{NC}_{\mathrm{T}}$ content, and which could be identified as an eddy. This is coherent with results obtained in analyses of the mesoscale circulation [Assenbaum and Reverdin, 2005] which show the presence of a stable cyclonic eddy in the area at least until April 2001.

\subsection{Upper Waters}

[10] The upper $1000 \mathrm{dbar}$ in this region of the Atlantic Ocean were occupied mainly by mode waters formed by deep winter convection resulting from heat loss at the sea surface [Mccartney and Talley, 1982]. In the POMME area, Eastern North Atlantic Central Water (ENACW) is found [Harvey, 1982; Pollard et al., 1996], present in Figure 3 as a cluster of points along the line between 9.5 and $15^{\circ} \mathrm{C}$ and 35.9-36.1. ENACW has two distinct subtypes of water according to their area of origin [Rios et al., 1992]: a colder, subpolar variety that moves southward off the Northwestern coast of the Iberian Peninsula, and a warmer, subtropical variety, which moves northward as a saline wedge in between the Azores archipelago and Portugal, right through

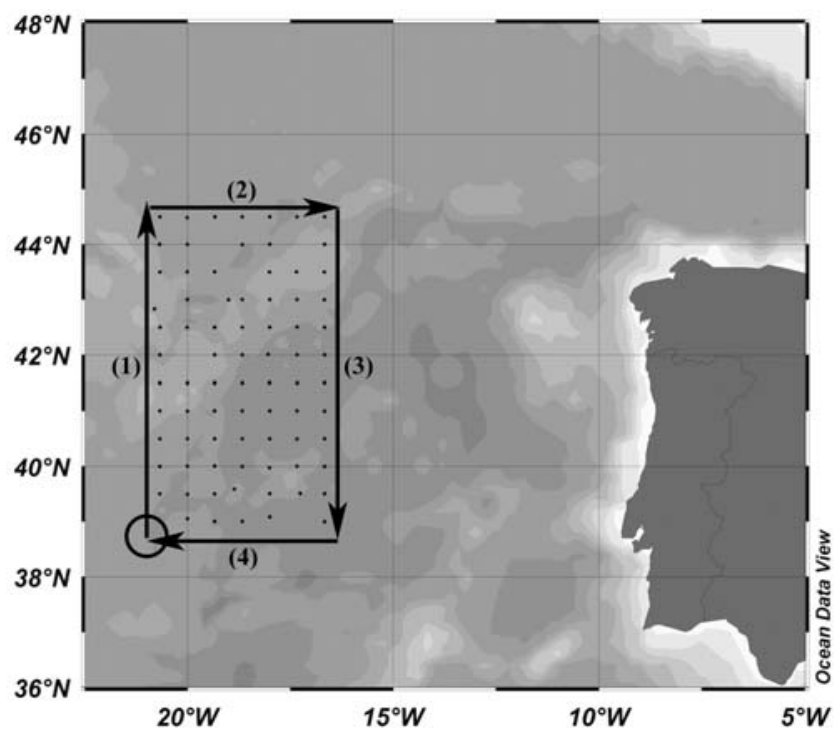

Figure 1. POMME region. Arrows indicate the sense of the vertical distributions followed to depict the POMME box walls. 

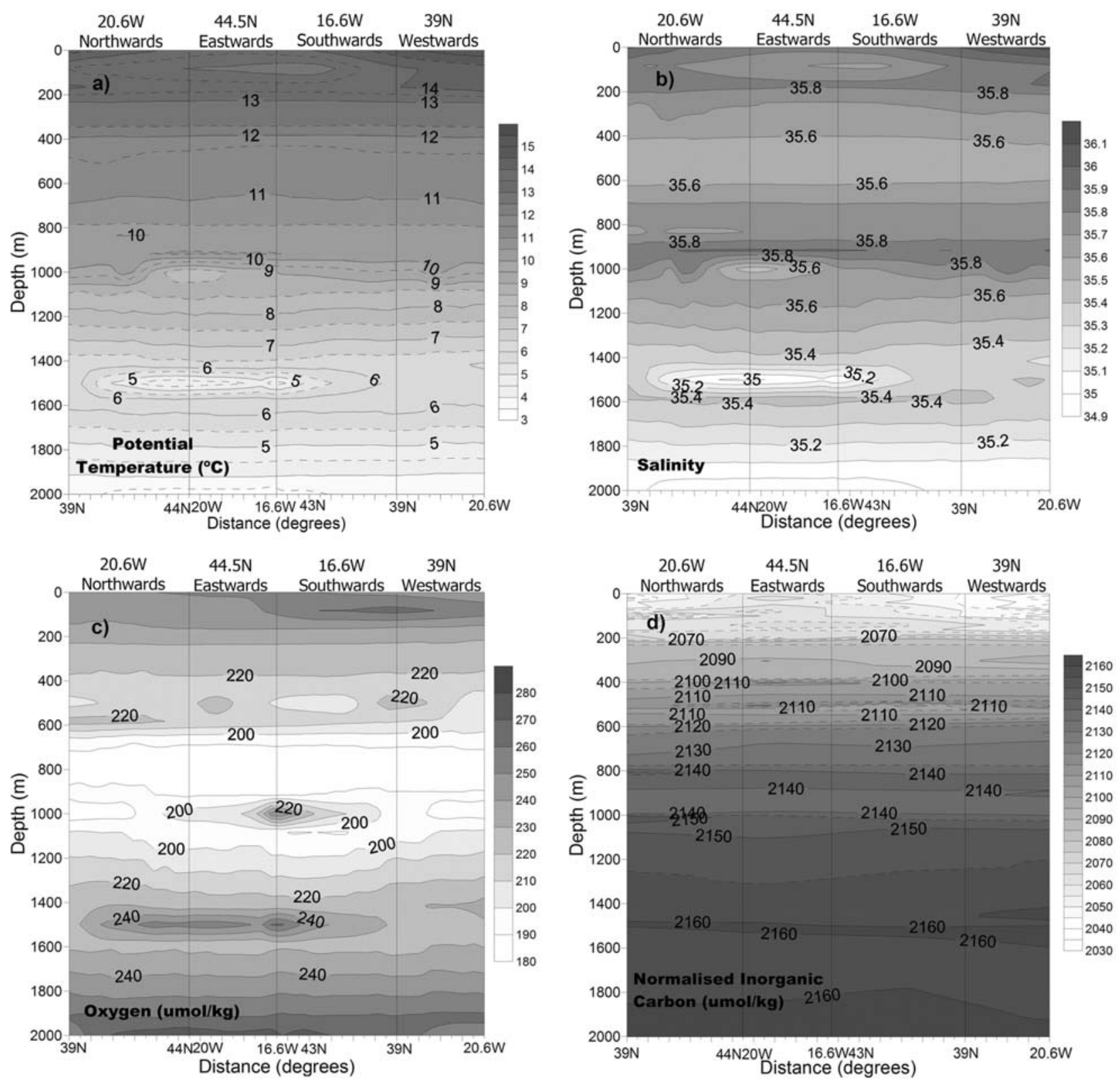

Figure 2. Vertical distribution of (a) potential temperature $\left(\theta,{ }^{\circ} \mathrm{C}\right)$, (b) salinity, (c) oxygen $\left(\mathrm{O}_{2}, \mu \mathrm{mol}\right.$ $\left.\mathrm{kg}^{-1}\right)$, and (d) normalized total inorganic carbon $\left(\mathrm{NC}_{\mathrm{T}}, \mu \mathrm{mol} \mathrm{kg}{ }^{-1}\right)$ along the POMME box walls in Figure 1 during POMME 1.

the POMME region. The former forms east of $20^{\circ} \mathrm{W}$ and north of $42^{\circ} \mathrm{N}$, with temperatures below $12.2^{\circ} \mathrm{C}$ [Harvey, 1982]; the latter is formed in the area of the Azores current, and presents higher temperatures, above $13^{\circ} \mathrm{C}$ [Pollard and $P u, 1985]$.

[11] The set of mode waters comprising subtropical ENACW would be modeled between the end-members ENACWt and H, as defined by Harvey [1982], and that comprising subpolar ENACW between $\mathrm{H}$ and ENACWp (Table 2 and Figure 3). The end-member $\mathrm{H}$ acts as the lower limit of subtropical ENACW and as the upper limit of subpolar ENACW, which is enclosed between $\mathrm{H}$ and its lower limit, ENACWp (9.42, 35.30).

[12] Central Waters in the POMME region appeared to diverge from the average values described in the literature, presenting salinity values which were lower than expected, and closer to the values observed in 1991 by Castro et al. [1998]. Reverdin et al. [2005] suggested that the differences observed might be the result of the formation of new water in the region, which would partially reset the $\theta-S$ properties in the northern section every winter. Highresolution model simulations [Da Costa et al., 2005] as well as available data sets [Pollard and Pu, 1985] suggest that the disparity is the result of large interannual variability in the characteristics of central waters [Perez et al., 1993]. This has been associated with the large-scale climate variability North Atlantic Oscillation, NAO [Marshall et al., 2001].

[13] To take this particularity into account, we defined two sets of ENACWt (Table 2), the first one being ENACWt ${ }_{1}$, cited in the literature, and a second one with 


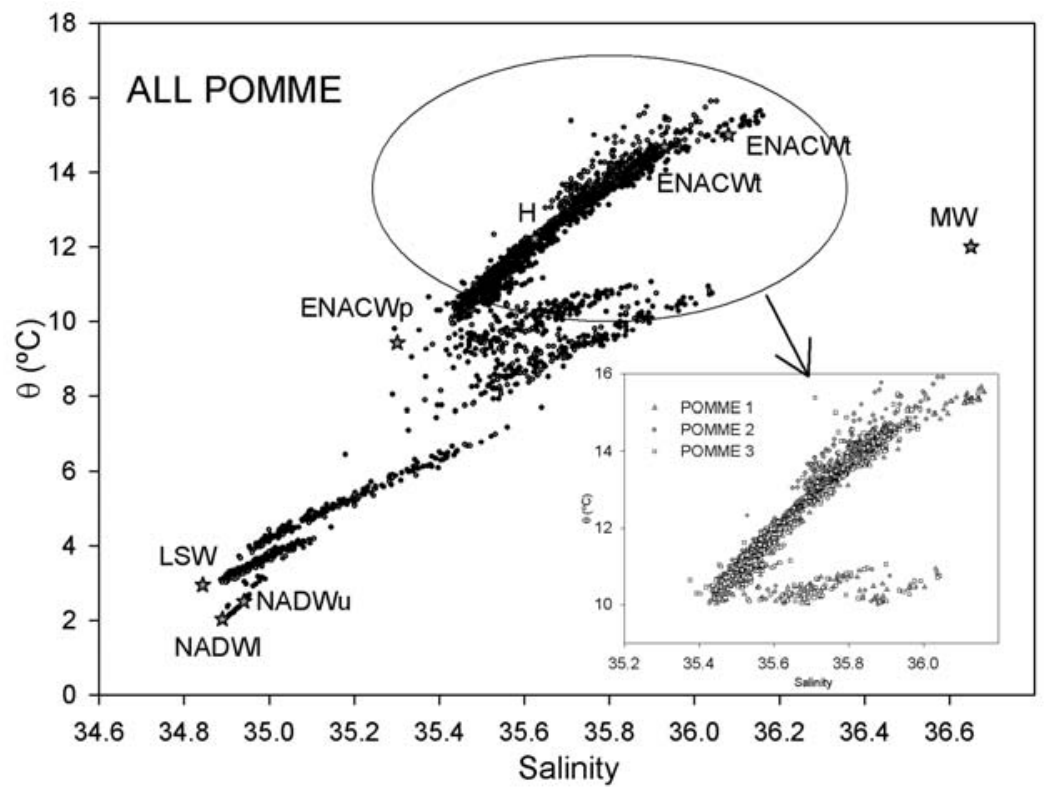

Figure 3. Potential temperature-salinity diagram for all POMME cruises. The physical characteristics of the source water types are also shown. ENACW stands for Eastern North Atlantic Central Water (subtropical subtype 1 (ENACWt ${ }_{1}$ ), subtropical subtype 2 (ENACWt $t_{2}$ ), and subpolar (ENACWp) types), $\mathrm{H}$ stands for the limit of the two types of ENACW, MW stands for Mediterranean Water, LSW for Labrador Sea Water, and NEADW for North East Atlantic Deep Water (lower (NEADWl) and upper (NEADWu)). The inset shows data for $\theta \geq 10^{\circ} \mathrm{C}$, with triangles for POMME 1, circles for POMME 2, and squares for POMME 3.

colder, less saline values, specific for this region, $\mathrm{ENACWt}_{2}$. The former appears mostly in the southwestern part of the POMME area, fixed at around 200-300 dbar, while the latter appears homogeneously distributed in the whole region in the first 200-300 dbar (Figure 5).

\subsection{Intermediate Waters}

[14] In the POMME region two main intermediate waters exist between 1000 and 2000 dbar: Mediterranean Water (MW) and Labrador Sea Water (LSW). The MW source water type (SWT, Table 2) is representative of the thermohaline characteristics after the Mediterranean overflow has sunk and stabilized at about $1000 \mathrm{~m}$ in the Atlantic Ocean [Arhan et al., 1994].
[15] LSW is traced through its low potential vorticity, salinity minimum, oxygen maximum and potential temperature of approximately $2.95^{\circ} \mathrm{C}$, although this has been highly variable through the last 25 years [Cunningham and Haine, 1995], and appears in the 1500-1800 dbar region (Figures 2 and 3).

\subsection{Deep Waters}

[16] Due to sampling restrictions, deep water samples are scarce and relate to the deepest stations sampled during POMME 1. In this area, North Eastern Atlantic Deep Water (NEADW) which is warmed Antarctic Bottom Water entering the eastern North Atlantic at the Vema Fracture Zone and the Romanche Trench [Dickson and Brown, 1994] is

Table 2. Source Water Types Considered: Physical and Chemical Characteristics, Errors, and Weights ${ }^{\mathrm{a}}$

\begin{tabular}{lccccccc}
\hline \multicolumn{1}{c}{ SWT } & $\theta\left({ }^{\circ} \mathrm{C}\right)$ & Salinity & $\mathrm{NO}_{3}\left(\mu \mathrm{mol} \mathrm{kg}^{-1}\right)$ & $\mathrm{PO}_{4}\left(\mu \mathrm{mol} \mathrm{kg}^{-1}\right)$ & $\mathrm{O}_{2}\left(\mu \mathrm{mol} \mathrm{kg}^{-1}\right)$ & $\mathrm{C}_{\mathrm{T}}\left(\mu \mathrm{mol} \mathrm{kg}^{-1}\right)$ & $\mathrm{A}_{\mathrm{T}}\left(\mu \mathrm{mol} \mathrm{kg}^{-1}\right)$ \\
\hline ENACWt $_{1}$ & $15.00 \pm 0.15$ & $36.08 \pm 0.02$ & $0.64 \pm 0.3$ & $0.06 \pm 0.05$ & $247 \pm 3$ & $2092 \pm 4$ & $2362 \pm 3$ \\
ENACWt & $14.68 \pm 0.13$ & $35.93 \pm 0.02$ & $2.85 \pm 0.3$ & $0.17 \pm 0.05$ & $248 \pm 3$ & $2098 \pm 4$ & $2355 \pm 3$ \\
$\mathrm{H}$ & $12.22 \pm 0.13$ & $35.62 \pm 0.02$ & $6.92 \pm 0.3$ & $0.42 \pm 0.05$ & $261 \pm 3$ & $2107 \pm 4$ & $2335 \pm 3$ \\
ENACWp & $9.42 \pm 0.15$ & $35.30 \pm 0.01$ & $9.47 \pm 0.2$ & $0.60 \pm 0.05$ & $278 \pm 2.5$ & $2108 \pm 2$ & $2319 \pm 1$ \\
MW & $11.99 \pm 0.03$ & $36.65 \pm 0.005$ & $4.15 \pm 0.2$ & $0.24 \pm 0.02$ & $260 \pm 2$ & $2151 \pm 3$ & $2429 \pm 3$ \\
LSW & $2.95 \pm 0.15$ & $34.84 \pm 0.01$ & $12.69 \pm 0.2$ & $0.90 \pm 0.05$ & $322 \pm 2.5$ & $2121 \pm 2$ & $2298 \pm 1$ \\
NEADWu & $2.51 \pm 0.03$ & $34.94 \pm 0.003$ & $12.94 \pm 0.2$ & $0.85 \pm 0.02$ & $327 \pm 1.2$ & $2132 \pm 2$ & $2329 \pm 2$ \\
NEADWl & $2.03 \pm 0.03$ & $34.89 \pm 0.003$ & $13.54 \pm 0.2$ & $0.95 \pm 0.02$ & $331 \pm 1.2$ & $2142 \pm 2$ & $2359 \pm 2$ \\
W & 10 & 9 & 3 & 0.92 & 3 & 2 \\
$\mathrm{R}^{2}$ & 0.9997 & 0.9990 & 0.9907 & 0.9705 & 0.9897 & 0.9818 & 0.9700 \\
SD & 0.05 & 0.009 & 0.5 & 0.06 & 2 & 4 & 2
\end{tabular}

${ }^{a}$ Here SWT is source water types and W is weights. Correlation coefficient $\left(\mathrm{R}^{2}\right)$ and standard error $(\mathrm{SD})$ of the regression between the measured and modeled variable. Number of data is 2203. ENACW stands for Eastern North Atlantic Central Water (subtropical subtype $1\left(\mathrm{ENACWt}_{1}\right)$, subtropical subtype 2 (ENACWt $)$, and subpolar (ENACWp) types), H stands for the limit of the two types of ENACW, MW stands for Mediterranean Water, LSW for Labrador Sea Water, and NEADW for North East Atlantic Deep Water (lower (NEADWl) and upper (NEADWu)). 
Table 3. Mean Geostrophic Velocities Estimated Between Pairs of Stations Along the Walls of the POMME Region for Each Cruise From 0 to 2000 dbar $^{\mathrm{a}}$

\begin{tabular}{lccc}
\hline Transect & POMME 1 & POMME 2 & POMME 3 \\
\hline $20.6^{\circ} \mathrm{W}$ & 0.16 & -0.44 & -0.25 \\
$44.5^{\circ} \mathrm{N}$ & 1.03 & 1.38 & 1.07 \\
$16.6^{\circ} \mathrm{W}$ & 0.46 & -0.21 & 1.19 \\
$39^{\circ} \mathrm{N}$ & 0.35 & 1.33 & 1.86 \\
\hline
\end{tabular}

${ }^{\mathrm{a}}$ Mean geostrophic velocities are given in $\mathrm{cm} / \mathrm{s}$. Positive (negative) values correspond to inflow (outflow) into the region.

found. For the purposes of this work we defined NEADW as the line between upper and lower NEADW, NEADWu and NEADWl, respectively (Table 2).

\subsection{Mixing Analysis}

[17] The water mass structure in the POMME region was solved through the use of an extended Optimum Multiparameter (OMP) analysis [Karstensen and Tomczak, 1998; Alvarez et al., 2004]. The OMP method consists on quantifying the mixture of a set of SWTs that makes up a given water parcel/sample. Biochemical characteristics (Table 2) were not predefined values taken from the literature, but were instead calculated through the iterative process in OMP, obtaining the types that better fit the cruise data [Alvarez et al., 2004].

[18] A detailed description of the process as well as the constraints used and the reliability and robustness of the analysis can be found in the auxiliary material. ${ }^{1}$

\section{Determination of the Geostrophic Circulation and Water Mass Transports}

[19] The geostrophic velocity field was calculated applying the Ocean Data View (ODV) thermal wind equations (http://odv.awi.de) to the CTD data averaged every 20 dbars. The level of no motion selected was $2000 \mathrm{dbar}$, the deepest common pressure available to all the stations. During a preparatory POMME cruise, a series of deep ADCP-L profiles were performed in the region. A study of the mean current profile estimated from these data showed average velocity values of $0.35 \pm 3.02 \mathrm{~cm} / \mathrm{s}$ at $2000 \mathrm{dbar}$, which supported the selection of $2000 \mathrm{dbar}$ as level of no motion. [Sy, 1988] found a level of no motion of 2000 dbars between 24 and $53^{\circ} \mathrm{N}$ using inverse modeling.

[20] The velocity field showed high variability, with patterns changing from cruise to cruise. The averaged velocity values across each section (Table 3 ) suggested higher velocities in a north-south direction (across $39^{\circ} \mathrm{N}$ and $44.5^{\circ} \mathrm{N}$ ). In POMME 2 and POMME 3 most of the variability observed within the sections could be linked to eddy activity; changes in current direction were often in agreement with the location of the eddies present in the area, described in detail by Le Cann et al. [2005].

[21] Additionally, we used altimetry products to assess the variability observed. Satellite altimetry data provide a homogeneous time series since 1992. We obtained Maps of Absolute Dynamic Topography (MADT) to estimate the

\footnotetext{
${ }^{1}$ Auxiliary materials are available in the HTML. doi:101029/ 2008JC005212.
}

absolute geostrophic velocities in the area. The altimeter products were produced by Ssalto/Duacs and distributed by Aviso, with support from Cnes (http://www.aviso.oceanobs. com/). The MADT represent the sum of the Mean Dynamic Topography (in this case Rio05, produced by $C L S$ Space Oceanography Division) and the Sea Level Anomalies $(\mathrm{ADT}=\mathrm{MDT}+\mathrm{SLA})$. They have a $1 / 3^{\circ}$ spatial resolution and a 7 day temporal resolution. The absolute geostrophic velocities obtained for the southern limit of the box $\left(39^{\circ} \mathrm{N}\right)$ for the year 2001 (Figure 4a) are in good agreement with our estimations and show how the direction of the velocities changed throughout the year, alternating between a southward and a northward direction. Figure $4 \mathrm{~b}$, which shows the transport structure across this section in the three cruises shows similar variability in the directions estimated. Figure 4a shows a westward phase propagation. This is most likely due to the eddy propagation pattern in the region. Le Cann et al. [2005] carried out a thorough study of eddy structures in the area through the use of altimetry combined with in situ data and their results also suggest that eddies move westward or southwestward in the region. Given the large number of eddies coexisting in the area, complex interactions between them and the mass transports are to be expected. As a result of the nonstationary nature of eddies in space and time, trying to extrapolate seasonal patterns will be difficult in this area with the available data.

[22] SWT contributions were obtained at bottle depths in every station, while velocity profiles were obtained every 20 dbars in the middle of every two stations. Consequently, SWT distributions were linearly interpolated every 20 dbars and averaged every two stations. The transport of any water mass in the region was calculated as the top to 2000 dbars and lateral integral, along the POMME box sections, of the geostrophic velocity values times the water mass contribution. The mass transport in the seasonal thermocline was attributed to the SWT immediately below. The direction of the water mass transports at each depth was given by the sign of the corresponding geostrophic velocity. Mass transports were considered positive when entering the POMME box and the total contribution was calculated as the vectorial addition of the transport across each wall.

\section{Results and Discussion}

\subsection{Distribution of Water Masses}

[23] The mean SWT contributions along the sections for each POMME cruise are shown in Figure 5. ENACW is the sum of the four end-members: ENACWt 1 and 2, $\mathrm{H}$ and ENACWp. ENACW dominated in the upper $1000 \mathrm{dbar}$, where the effect of the front was visible, and therefore, where north-south differences were visible (data not shown). The maximum contribution of $\mathrm{H}$ represents the lower limit of the subtropical ENACW. According to its location, the subtropical branch of ENACW concentrated in the surface layers, with its lower extreme oscillating between 300 and 400 dbar depending on the cruise. During the POMME 1, subtropical ENACW was evenly distributed in the whole region in the upper $400 \mathrm{dbar}$; in April it was restricted to $350 \mathrm{dbar}$ and in the western limit of the box, the intrusion of the subpolar branch of ENACW increased the mixing of both branches. During POMME 3, subtropical ENACW had its lower limit displaced to shallower depths, 
a)

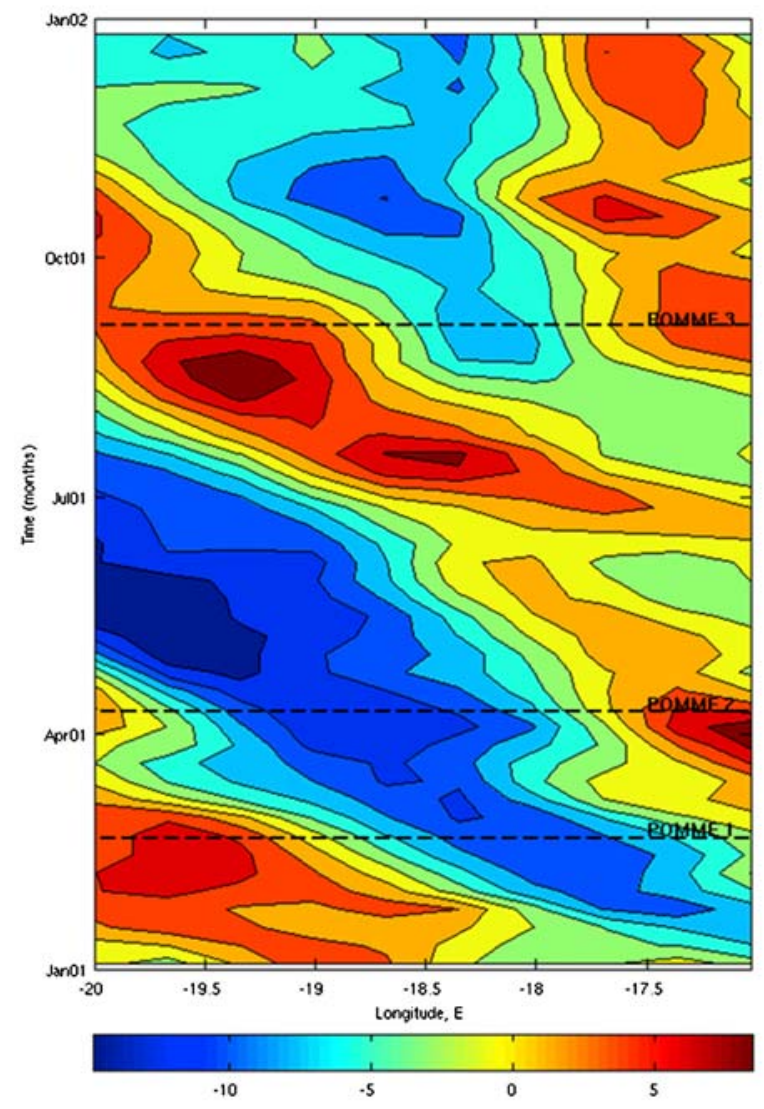

b)
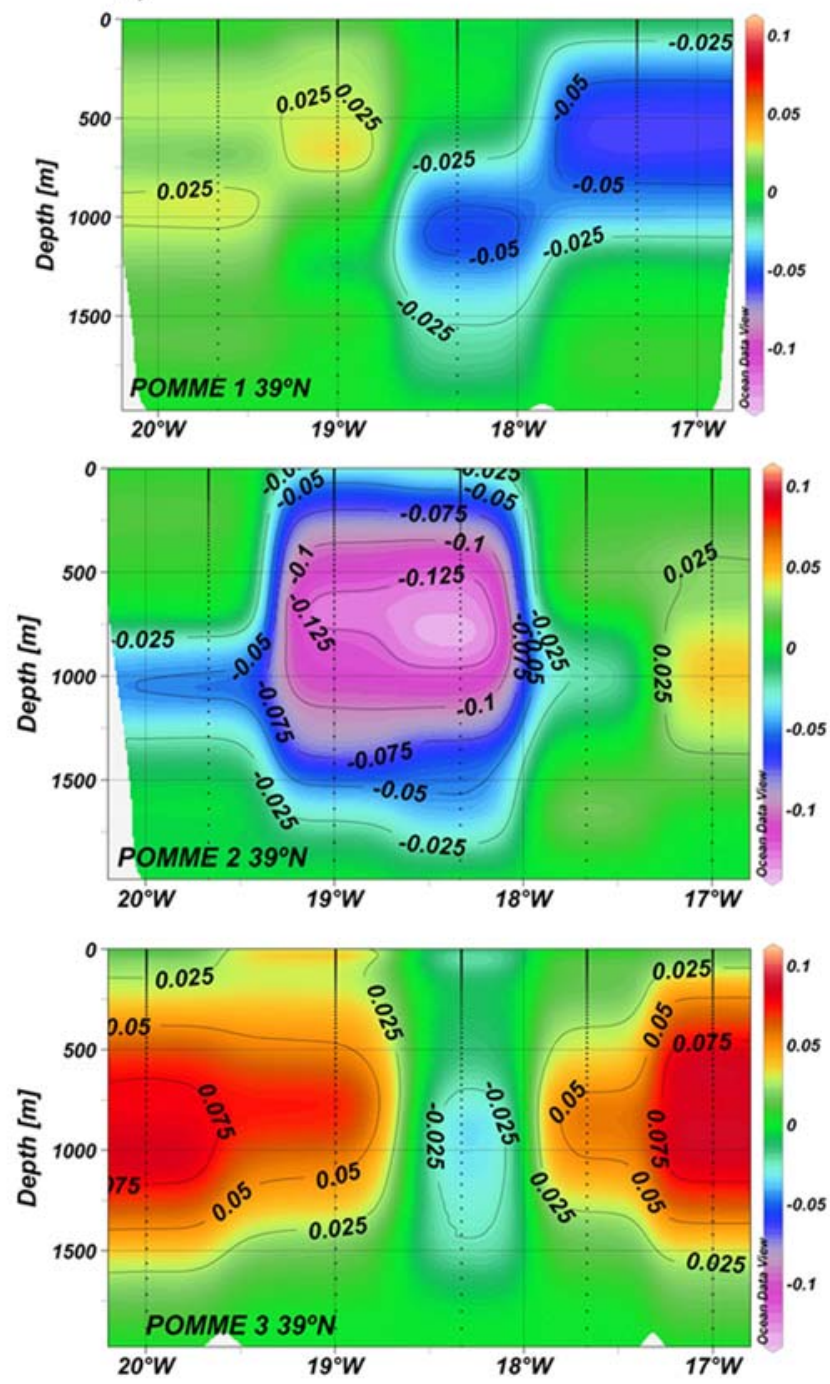

Figure 4. (a) Map of absolute geostrophic velocities (meridional component, $\mathrm{V}, \mathrm{cm} / \mathrm{s}$ ) through section $39^{\circ} \mathrm{N}$ over the year 2001 computed from altimetry data. The dashed lines indicate the time when the POMME cruises took place. (b) Transports (Sv) through the section at $39^{\circ} \mathrm{N}$, in the southern wall of the POMME box estimated for POMME 1, 2, and 3. Positive values indicate a flow northward (into the box).

close to 300 dbar. Throughout 2001, subtropical ENACW distribution in the area was displaced upward by approximately $100 \mathrm{dbar}$, as the subduction of the subpolar ENACW increased the fraction of this branch present in the upper layers of the ocean.

[24] This breed of ENACW had its area of maximum distribution at around 800 dbar throughout the year, although it was during the POMME 3 that it had higher relative contributions over a wider depth range. The highest relative contributions (60\% and higher) during POMME 1, though still centered around $800 \mathrm{dbar}$, were restricted to only a few dozen decibars, while in POMME 3 this area of maximum influence extended over approximately $100 \mathrm{~m}$ in depth, particularly in the southern part of the area. Leffanue and Tomczak [2004] have also suggested that the presence of warm or cold eddies in an area, as is the case in the
POMME region, might explain part of the variability observed for a given SWT contribution within a same sampling period.

[25] MW appears below the subpolar ENACW. The strongest relative contributions at a particular depth were observed in February (Figure 5b), when contributions reached values of $50 \%$ of the water composition in the 900 dbar range. Nevertheless, when the added contributions of MW over the whole water column were considered, the overall role of MW was more important during POMME 3, when contributions of $30 \%$ or higher could be found down to $1400 \mathrm{dbar}$, whereas for POMME 1 and POMME 2 these proportions were mainly restricted to $1200 \mathrm{dbar}$ or higher. This distribution of depths is coherent with the results published by Maze et al. [1997] and Arhan and King [1995]. The presence of MW in this area is the result of the com- 

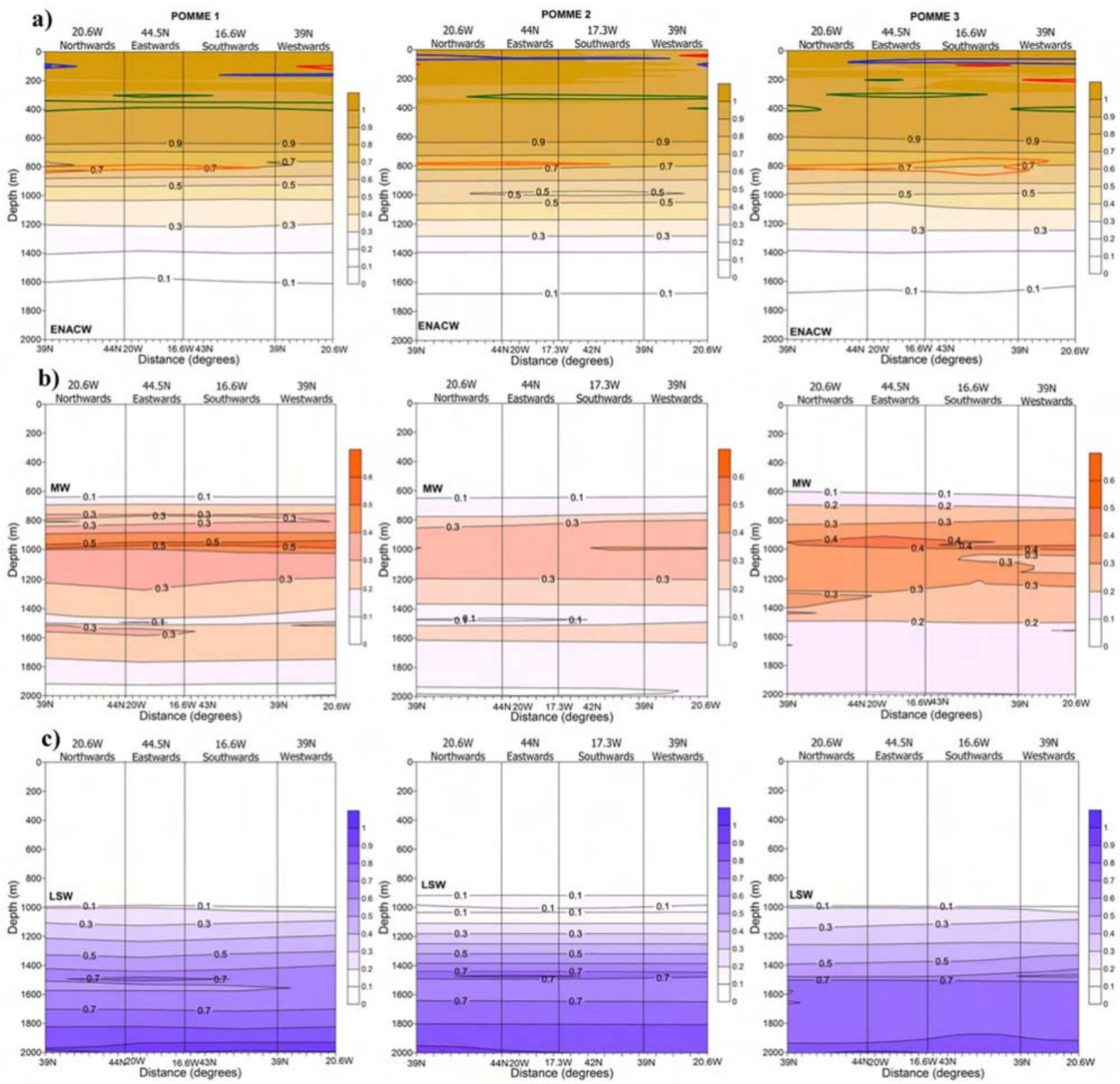

Figure 5. Vertical distribution of the water mass contribution along the POMME box walls following the sense in Figure 1 and for the three POMME cruises. (a) ENACW contribution. The maximum contribution of each type of ENACW is represented by a colored line: red for ENACWt ${ }_{1}$, blue for $\mathrm{ENACWt}_{2}$, green for $\mathrm{H}$, and orange for ENACWp. (b) Mediterranean Water and (c) Labrador Sea Water.

bined effect of meddies that meander off the Portuguese coast and the regular outflow spreading through the strait of Gibraltar [Zenk and Armi, 1990; Peliz et al., 2005].

[26] The lower section of the region in study was mainly occupied by LSW, which was homogeneously distributed throughout the year, both in depth and in meridional distribution. Its proportion in the 1800-2000 dbar depth was very high reaching contributions of $80-90 \%$, in good agreement with Pingree [1973], who described how LSW could reach the eastern basin of the North Atlantic in high proportions.

[27] In the February cruise when deeper than $2000 \mathrm{~m}$ water were included, NEADW appeared very briefly, but its influence lies beyond the sampling region of this study and no reliable conclusions could be inferred.

\subsection{Mass Transports}

[28] Our results suggested that fluxes vary considerably throughout the year. Changes in flux direction and in magnitude from one cruise to the other, particularly between POMME 1 and POMME 3, when there was a net change in direction, supported the idea that this area presents high variability. In February, the flux through section $39^{\circ} \mathrm{N}$ (Figure 4b) was very low, with discrete transport values ranging from -0.04 to $0.03 \mathrm{~Sv}$, and a small flow northward in the western end compensated with a higher southward 
a)
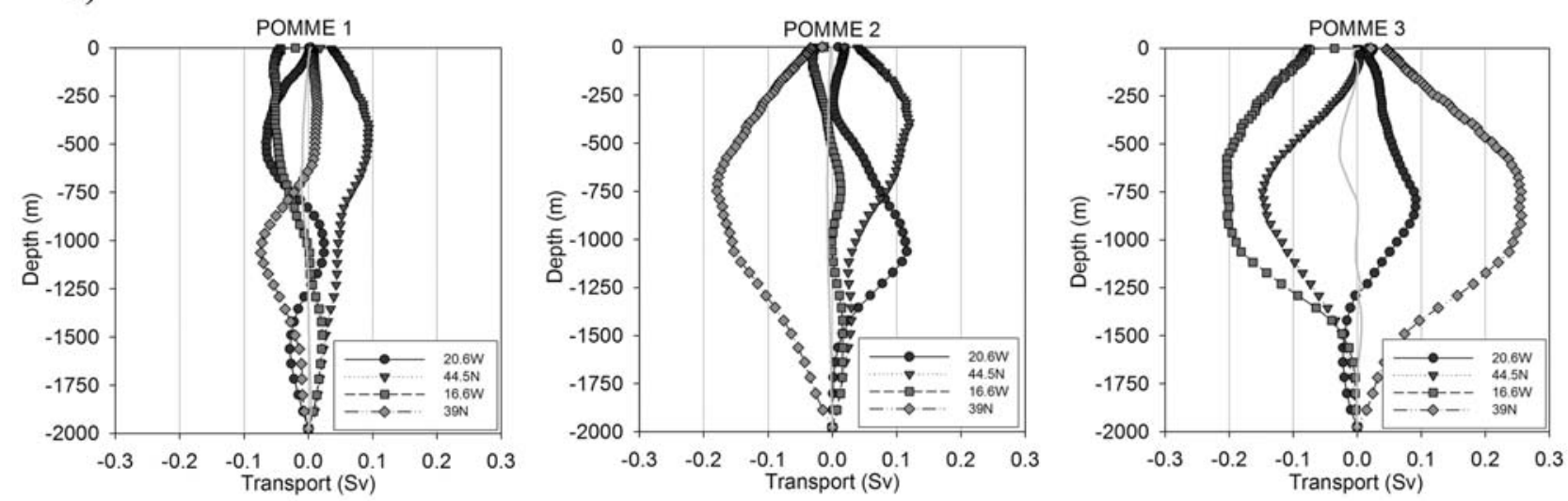

b)
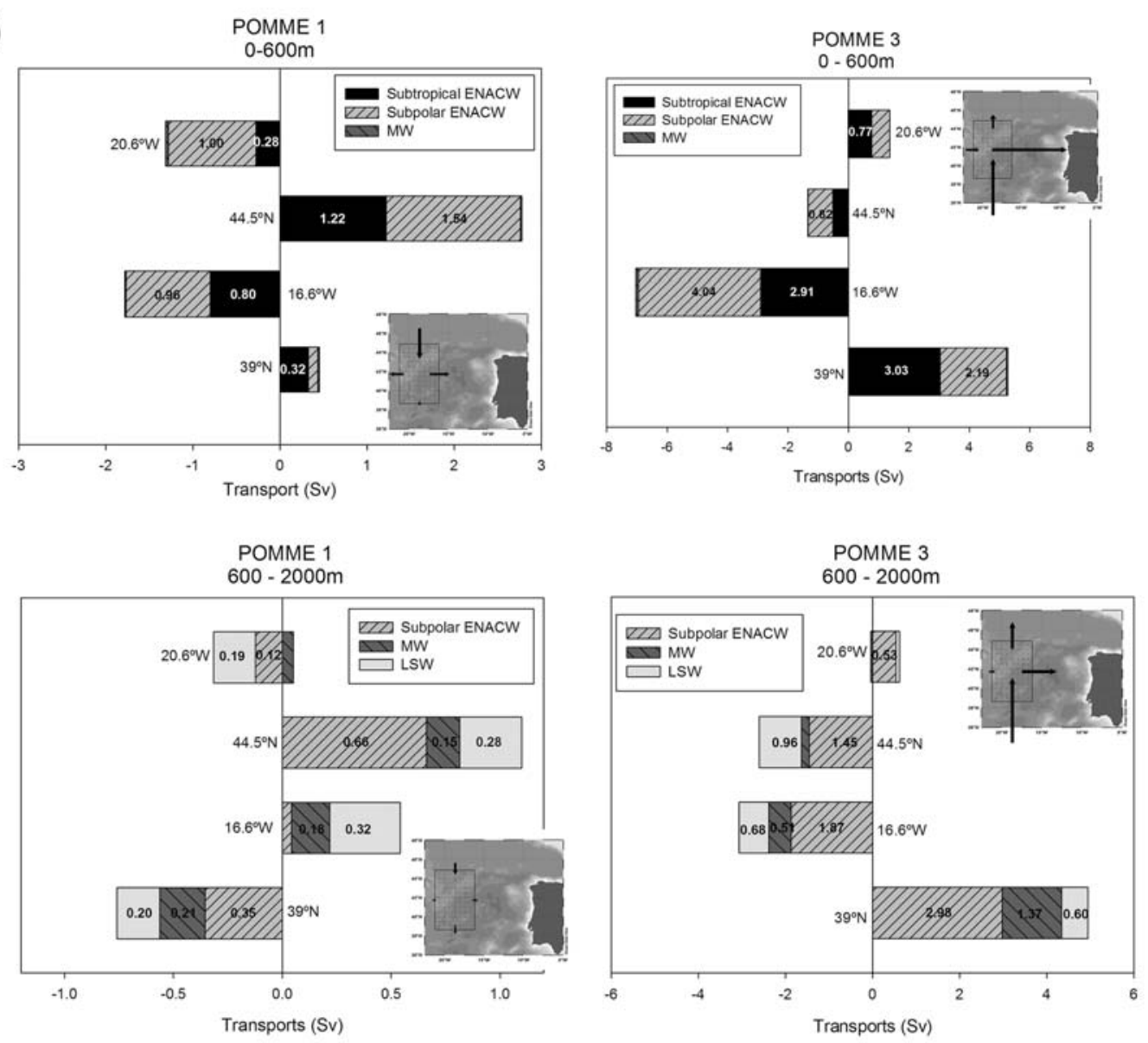

Figure 6. (a) Profiles of mass transport (Sv) for the four walls considered estimated for POMME 1, 2, and 3. Positive values indicate inflow into the box. Negative values indicate outflow. The thin gray line is a profile of the budget, calculated as the added contributions from each wall. (b) Water mass contributions to the mass transport (Sv) across the POMME box walls following the sense of Figure 1 for POMME 1 and 3, in the upper $600 \mathrm{~m}$ and in intermediate depths between 600 and $2000 \mathrm{~m}$. The inset shows a schematic representation of the POMME box. The arrows indicate the magnitude and direction of the computed transports.

flow in the eastern corner. In April, the flow intensified, with discrete values ranging from -0.13 to $0.14 \mathrm{~Sv}$ and most of the flow heading southward. The pattern had changed again by POMME 3 , and the main transport was heading northward.
[29] Figure 6a summarizes the transports calculated for the sections considered for each cruise. Transport values were horizontally integrated for each section at every given depth. Figure 6a provides transport direction and intensity, with positive values indicating an inflow into the POMME 
Table 4. Total Transports Calculated Across Each Wall of the POMME Box for Each Cruise ${ }^{a}$

\begin{tabular}{lccc}
\hline Transect & POMME 1 & POMME 2 & POMME 3 \\
\hline $20.6^{\circ} \mathrm{W}$ & -1.50 & 2.04 & 2.22 \\
$44.5^{\circ} \mathrm{N}$ & 3.82 & 4.55 & -3.22 \\
$16.6^{\circ} \mathrm{W}$ & -2.14 & -0.58 & -8.27 \\
$39^{\circ} \mathrm{N}$ & -0.38 & -6.32 & 8.33 \\
\hline
\end{tabular}

${ }^{\text {a }}$ Total transports are given in Sv and the POMME box is given from top to 2000 dbar. Positive (negative) values correspond to inflow (outflow) into the region.

region, and negative values indicating an outflow. The thin, gray line represents the sum of the inflows and outflows with depth. Transports did not cancel out completely (Table 4), and the net budget for the POMME area oscillated between -0.2 and $-0.4 \mathrm{~Sv}$. Part of this error was associated to the lack of data below $2000 \mathrm{dbar}$, which prevented a full study of the transports from top to bottom and to recirculation in the upper layers as a result of the presence of eddies in the border sections.

[30] During POMME 1 (Figure 6a, POMME 1), transport rates were low and heading mainly southward; the highest flow integrated for the whole section, took place across $44.5^{\circ} \mathrm{N}$, with an average inflow of $3.82 \mathrm{~Sv}$ (Table 4). Transports across the upper and deeper layers showed opposing trends in the southern $\left(39^{\circ} \mathrm{N}\right)$ and western $\left(20.6^{\circ} \mathrm{W}\right)$ walls of the box, an indicator of the different directions in which each water mass was moving (Figure 6b). The southward direction at this time of the year was in agreement with the transport proposed by Saunders [1982], who calculated $2.5 \mathrm{~Sv}$ flowing southward across $41.5 \mathrm{~N}$, and with Paillet and Mercier [1997], who estimated that southward branches of North Atlantic current (NAC) transported of up to $17 \mathrm{~Sv}$ top to bottom at $40^{\circ} \mathrm{N}$ (over a larger longitude range).

[31] During POMME 2, the transport rates had increased considerably, particularly at middepths where in some cases $\left(39^{\circ} \mathrm{N}\right)$ the transport was twice that of POMME 1 (Figure 6a, POMME 2). The southward transport intensified and we estimated an outflow of $6.3 \mathrm{~Sv}$ through the southern limit of the box, compared to less than $1 \mathrm{~Sv}$ during POMME 1 (Table 4). Figures $4 \mathrm{~b}$ and 6a (POMME 2) illustrate how this outflow took place mainly at approximately $800 \mathrm{dbar}$ in the domain of subpolar ENACW. The water entering the box through $20.6^{\circ} \mathrm{W}$ was also interpreted as subpolar ENACW that subducted in the region.

[32] In the September cruise, the direction of the flow had shifted and the transport was coming in through $39^{\circ} \mathrm{N}$ and $20.6^{\circ} \mathrm{W}$ (northeastward, referred to as NE hereafter). Transport rates were the highest of the three cruises, with inflows of up to $8.8 \mathrm{~Sv}$. This would be in agreement with the general circulation pattern described by Paillet and Mercier [1997] for the NAC. However, we found no clear evidence of a general westward flow, except for a minor flow through the $20.6^{\circ} \mathrm{W}$ section during POMME 1 , in contrast to the circulation pattern proposed by Pollard and $P u$ [1985] and Pollard et al. [1996].

[33] The differences observed between POMME 1 and POMME 3 were indicative of the high variability that exists in the area. During the POMME experiment, several stable eddies were identified, some of which had lives of over 1 year [Le Cann et al., 2005]. The displacement of these eddies (some of which can have expressions deeper than 2000 dbar) across the sections studied would influence the transport estimations. Studies carried out in the upper $400 \mathrm{~m}$ of the area with lagrangian data concluded that circulation in the upper layers was controlled by mesoscale eddies [Assenbaum and Reverdin, 2005]. Large-scale changes in the locations of the Azores front and the subtropical and subpolar gyres can also affect the transport fluxes [Kase and Siedler, 1982; Curry and McCartney, 2001; Marshall et al., 2001; Siedler et al., 2005]. Figures 4b (POMME 3) and 6a (POMME 3) show that the highest mass transport during POMME 3 took place in the $1000 \mathrm{dbar}$ range, as a result of a strong input of Mediterranean water into the box, which can also be present in the area by means of meddies [Siedler et al., 2005].

[34] By combining the mass transport calculations with the water mass quantification output results from OMP, we were able to determine the relative contribution of each water mass to the geostrophic flows. Figure $6 \mathrm{~b}$ shows a summary of the distributions of mass transports by water mass and depth range, for each of the walls of the POMME box during POMME 1 and POMME 3.

[35] The ENACW in this area extended its main region of influence down to $600 \mathrm{dbar}$, so we adopted this depth as the limit between the upper and the intermediate layers.

[36] Water masses in the upper $600 \mathrm{dbar}$ were advected mainly southward during POMME 1 and NE during POMME 3 and involved almost exclusively ENACW (Figure 6b). During POMME 1, $2.76 \mathrm{~Sv}$ of ENACW (the combined transports of the subtropical and subpolar branches) entered the box across $44.5^{\circ} \mathrm{N}$. The subtropical EN$\mathrm{ACW}$ is formed during winter in this area, which can explain why $0.5 \mathrm{~Sv}$ less subtropical ENACW left the box than entered it. The relative importance of the two branches of ENACW in the upper 600 dbar did not vary significantly between POMME 1 and 3; each was responsible for roughly half the transport taking place.

[37] The subpolar ENACW was present both in the upper and intermediate layers, so over the $2000 \mathrm{dbar}$ considered in this study its contribution to transport in the area was higher than that of subtropical ENACW. The changes observed in the direction and magnitude of the transports were reflected also in the relative importance of subpolar ENACW. Transports in the intermediate layer, from 600 to $2000 \mathrm{dbar}$ (Figure 6b, 600-2000 m), were determined by the presence of subpolar ENACW, MW and LSW. During POMME 1, water flowed southeastward on average, whereas during POMME 3 the main flow headed NE. Subpolar ENACW was still the most important contributor to transport at this depth. During the February cruise, the NE inflow transported almost as much ENACW as LSW (0.7 to $0.6 \mathrm{SV})$, but during POMME 3, ENACW transport was almost 5 times higher, $4.9 \mathrm{~Sv}$, representing $61 \%$ of the total for that range of depths. An interesting situation was observed with MW: although transport was low for POMME 1, an input of $0.4 \mathrm{~Sv}$ was computed, coming from the north. This was likely the result of a meddy drifting into the area. In the last cruise, the main input of MW into the region came from the south through $39^{\circ} \mathrm{N}$ and was estimated to be approximately 1.6 Sv (Figure 6b, 600-2000 m). On the other hand, the relative importance of MW compared to LSW increased for this cruise, when their inputs were similar. Nevertheless, the 
overall contribution of LSW to transport was probably larger when transports below $2000 \mathrm{dbar}$ (where LSW is expected to play a bigger role) are taken into consideration. The northward transport found by Saunders [1982] and Paillet and Mercier [1997] at the 1000 dbar level was found only for POMME 3, but not for the previous ones. At the LSW level, on the other hand, we found a southwestward flow during the first two cruises, in agreement with Speer et al. [1999]. Our results were thus all shown to be in agreement with those proposed by previous authors depending on which cruise was considered, confirming the importance of carrying out studies of annual variability in highly dynamic areas such as POMME in order to correctly describe the transport structures.

[38] Having data from different times of the same year enabled us to calculate a mean transport trend for the year 2001. To do this, we worked out the average transport in the north-south (i.e., through sections $39^{\circ} \mathrm{N}$ and $44.5^{\circ} \mathrm{N}$ ) and east-west $\left(16.5^{\circ} \mathrm{W}\right.$ and $\left.22^{\circ} \mathrm{W}\right)$ directions. Concerning EN$\mathrm{ACW}$, our results for the year 2001 indicate an annual southeastward transport overall, in agreement with the results proposed by Gaillard et al. [2005] and Paillet and Mercier [1997]. At the 500 dbar level, we find a weak westward transport during POMME 1 (Figure 6a, POMME 1) in agreement with Le Cann et al. [2005], which is no longer found in the remaining cruises. We find no clear evidence of a sustained northward advection of ENACWt during POMME 1 or POMME 2, although during POMME 3 , a northward transport is observed. On an annual scale, this would support the hypothesis that this SWT is a result of the combined ENACW southward advection plus the subduction taking place in the region rather than a northward advection of ENACW . $_{\text {. }}$.

\section{Conclusions}

[39] The POMME hydrographic and chemical data set was used to make an estimation of the water mass distribution and transport patterns in the eastern North Atlantic during 2001. An extended Optimum MultiParameter analysis was applied to study the distribution of ENACW, MW and LSW in the upper $2000 \mathrm{dbar}$. The robustness of the model was tested and the model was able to reproduce the physical-chemical characteristics of the region reliably.

[40] The mixing structure along the walls of the POMME box was combined with the transport fields calculated for the first $2000 \mathrm{dbar}$ in order to determine the relative contribution of each water mass to the fluxes, as well as to evaluate the variations in the direction and magnitude of the flows estimated from the different cruises. Our results suggest considerable variability in the area during 2001. Transport rates during POMME 1 were low and headed southeastward, with a total inflow of $3.8 \mathrm{~Sv}$. The estimated transport rates increased for POMME 2, when $6.8 \mathrm{~Sv}$ were transported out of the region in a southward direction. During POMME 3, the mainstream flux flowed northeastward, with $8.8 \mathrm{~Sv}$ entering the box through the southern wall $\left(39^{\circ} \mathrm{N}\right)$. The presence of anticyclonic and cyclonic eddies as well as meddies crisscrossing the sections of the area of study, as documented in the literature of the POMME project, is expected to be play a major role in the variability observed between cruises.
[41] Transport in the upper layer was dominated by ENACW and headed southward during POMME 1 and NE during POMME 3. Subpolar ENACW was the main transport agent at the intermediate layer. In February, MW and LSW were responsible for $60 \%$ of the transport each; in the third cruise, the contribution of MW increased with respect to LSW, which had a higher relative importance in POMME 1 compared to POMME 3.

[42] Our results show that in regions of high physical variability, such as the POMME area, the estimation of the transports taking place must take into consideration that results obtained for one cruise alone might not be representative of the situation on an annual scale. This is a relevant consideration to make also when applied to the computation of annual biogeochemical transports (L. Barbero et al., paper in preparation, 2010). When this variability was included as a factor in the flux studies, our results were able to explain some of the previous disagreements concerning flux direction in the region.

[43] Acknowledgments. The authors are grateful for Laurent Mémery's invitation to participate in the POMME project. We would like to thank the crew of the R/V L'Atalante and Thalassa and are indebted to I. Rodriguez-Ucha and M. J. Rodriguez-Somoza for their help with sampling. We thank P. Lherminier for providing ADCP profile data and ideas on how to estimate an adequate level of no motion and A. Spadone for very helpful suggestions concerning the use of altimetry data. The article was much improved from the comments of two anonymous reviewers. This research was funded by a Ph.D. fellowship granted by the Universidad de Las Palmas de Gran Canaria, as well as by Ministerio de Ciencia y Tecnología PGC2000-2185-E, the Canary Island Government, and Cabildo de Gran Canaria.

\section{References}

Alvarez, M., F. F. Perez, H. Bryden, and A. F. Rios (2004), Physical and biogeochemical transports structure in the North Atlantic subpolar gyre, J. Geophys. Res., 109, C03027, doi:10.1029/2003JC002015.

Arhan, M., and B. King (1995), Lateral mixing of the Mediterranean Water in the eastern North Atlantic, J. Mar. Res., 53, 865-895, doi:10.1357/ 0022240953212990.

Arhan, M., A. C. Deverdiere, and L. Memery (1994), The eastern boundary of the subtropical North Atlantic, J. Phys. Oceanogr., 24, 1295-1316, doi:10.1175/1520-0485(1994)024<1295:TEBOTS $>2.0 . C O ; 2$.

Assenbaum, M., and G. Reverdin (2005), Near real-time analyses of the mesoscale circulation during the POMME experiment, Deep Sea Res. Part I, 52, 1345-1373, doi:10.1016/j.dsr.2005.03.006.

Bower, A. S., B. Le Cann, T. Rossby, W. Zenk, J. Gould, K. Speer, P. L. Richardson, M. D. Prater, and H. M. Zhang (2002), Directly measured mid-depth circulation in the northeastern North Atlantic Ocean, Nature, 419, 603-607, doi:10.1038/nature01078.

Castro, C. G., F. F. Perez, S. E. Holley, and A. F. Rios (1998), Chemical characterisation and modelling of water masses in the northeast Atlantic, Prog. Oceanogr., 41, 249-279, doi:10.1016/S0079-6611(98)00021-4.

Cunningham, S. A., and T. W. N. Haine (1995), Labrador Sea Water in the eastern North Atlantic. 1. A synoptic circulation inferred from a minimum in potential vorticity, J. Phys. Oceanogr., 25, 649-665, doi:10.1175/1520-0485(1995)025<0649:LSWITE >2.0.CO;2.

Curry, R. G., and M. S. McCartney (2001), Ocean gyre circulation changes associated with the North Atlantic Oscillation, J. Phys. Oceanogr., 31, 3374-3400, doi:10.1175/1520-0485(2001)031<3374:OGCCAW $>2.0$. $\mathrm{CO} ; 2$.

Da Costa, M. V., H. Mercier, and A. M. Treguier (2005), Effects of the mixed layer time variability on kinematic subduction rate diagnostics, J. Phys. Oceanogr., 35, 427-443.

Dickson, A. G., and F. J. Millero (1987), A comparison of the equilibrium constants for the dissociation of carbonic-acid in seawater media, Deep Sea Res., 34, 1733-1743, doi:10.1016/0198-0149(87)90021-5.

Dickson, R. R., and J. Brown (1994), The production of North Atlantic Deep-Water: Sources, rates, and pathways, J. Geophys. Res., 99, 12,319-12,341, doi:10.1029/94JC00530. 
Dietrich, G., K. Kalle, W. Krauss, and G. Siedler (1980), General Oceanography, Engl. Transl., Wiley, Chichester, U.K.

Fernandez, C., P. Raimbault, N. Garcia, P. Rimmelin, and G. Caniaux (2005a), An estimation of annual new production and carbon fluxes in the northeast Atlantic Ocean during 2001, J. Geophys. Res., 110, C07S13, doi:10.1029/2004JC002616.

Fernandez, C., P. Raimbault, G. Caniaux, N. Garcia, and P. Rimmelin (2005b), Influence of mesoscale eddies on nitrate distribution during the POMME program in the northeast Atlantic Ocean, J. Mar. Syst., 55, 155-175, doi:10.1016/j.jmarsys.2004.08.007.

Fraga, F., A. F. Rios, F. F. Perez, and F. G. Figueiras (1998), Theoretical limits of oxygen: Carbon and oxygen: Nitrogen ratios during photosynthesis and mineralisation of organic matter in the sea, Sci. Mar., 62, 161168, doi:10.3989/scimar.1998.62n1-2161.

Gaillard, F., H. Mercier, and C. Kermabon (2005), A synthesis of the POMME physical data set: One year monitoring of the upper layer, $J$. Geophys. Res., 110, C07S07, doi:10.1029/2004JC002764.

Gonzalez-Davila, M., J. M. Santana-Casiano, L. Merlivat, L. BarberoMunoz, and E. V. Dafner (2005), Fluxes of CO2 between the atmosphere and the ocean during the POMME project in the northeast Atlantic Ocean during 2001, J. Geophys. Res., 110, C07S11, doi:10.1029/ 2004JC002763

Harvey, J. (1982), $\theta$-S relationships and water masses in the eastern North Atlantic, Deep Sea Res., 29, 1021-1033, doi:10.1016/0198-0149(82) 90025-5.

Karstensen, J., and M. Tomczak (1998), Age determination of mixed water masses using CFC and oxygen data, J. Geophys. Res., 103, 18,59918,609, doi:10.1029/98JC00889.

Kase, R. H., and G. Siedler (1982), Meandering of the sub-tropical front southeast of the Azores, Nature, 300, 245-246, doi:10.1038/300245a0.

Le Cann, B., M. Assenbaum, J. C. Gascard, and G. Reverdin (2005), Observed mean and mesoscale upper ocean circulation in the midlatitude northeast Atlantic, J. Geophys. Res., 110, C07S05, doi:10.1029/ 2004JC002768.

Leffanue, H., and M. Tomczak (2004), Using OMP analysis to observe temporal variability in water mass distribution, J. Mar. Syst., 48, 3-14, doi:10.1016/j.jmarsys.2003.07.004.

Marshall, J., Y. Kushner, D. Battisti, P. Chang, A. Czaja, R. Dickson, J. Hurrell, M. McCartney, R. Saravanan, and M. Visbeck (2001), North Atlantic climate variability: Phenomena, impacts and mechanisms, Int J. Climatol., 21, 1863-1898, doi:10.1002/joc.693.

Maze, J. P., M. Arhan, and H. Mercier (1997), Volume budget of the eastern boundary layer off the Iberian Peninsula, Deep Sea Res. Part I, 44 1543-1574, doi:10.1016/S0967-0637(97)00038-1.

Mccartney, M. S., and L. D. Talley (1982), The sub-polar mode water of the North Atlantic Ocean, J. Phys. Oceanogr., 12, 1169-1188, doi:10.1175/1520-0485(1982)012<1169:TSMWOT $>2.0$.CO;2.

Mehrbach, C., C. H. Culberson, J. E. Hawley, and R. N. Pytkowicz (1973), Measurements of the apparent dissociation constants of carbonic acid in seawater at atmospheric pressure, Limnol. Oceanogr., 18, 897-907.

Memery, L., G. Reverdin, J. Paillet, and A. Oschlies (2005), Introduction to the POMME special section: Thermocline ventilation and biogeochemical tracer distribution in the northeast Atlantic Ocean and impact of mesoscale dynamics, J. Geophys. Res., 110, C07S01, doi:10.1029/ 2005JC002976.

Paillet, J. (1999), Central water vortices of the eastern North Atlantic, $J$. Phys. Oceanogr., 29, 2487-2503, doi:10.1175/1520-0485(1999) 029<2487:CWVOTE $>2.0 . \mathrm{CO} ; 2$.
Paillet, J., and M. Arhan (1996), Shallow pycnoclines and mode water subduction in the eastern North Atlantic, J. Phys. Oceanogr., 26, 96-114, doi:10.1175/1520-0485(1996)026<0096:SPAMWS >2.0.CO;2.

Paillet, J., and H. Mercier (1997), An inverse model of the eastern North Atlantic general circulation and thermocline ventilation, Deep Sea Res. Part I, 44, 1293-1328, doi:10.1016/S0967-0637(97)00019-8.

Peliz, A., J. Dubert, A. M. P. Santos, P. B. Oliveira, and B. Le Cann (2005) Winter upper ocean circulation in the western Iberian Basin: Fronts, eddies and poleward flows: An overview, Deep Sea Res. Part I, 52, 621-646, doi:10.1016/j.dsr.2004.11.005.

Perez, F. F., C. Mourino, F. Fraga, and A. F. Rios (1993), Displacement of water masses and remineralization rates off the Iberian Peninsula by nutrient anomalies, J. Mar. Res., 51, 869-892, doi:10.1357/ 0022240933223891.

Pingree, R. D. (1973), Component of Labrador Sea Water in Bay of Biscay, Limnol. Oceanogr., 18, 711-718.

Pollard, R. T., and S. Pu (1985), Structure and circulation of the upper Atlantic Ocean northeast of the Azores, Prog. Oceanogr., 14, 443462, doi:10.1016/0079-6611(85)90022-9.

Pollard, R. T., M. J. Griffiths, S. Cunningham, J. F. Read, F. F. Pérez, and A. F. Ríos (1996), Vivaldi 1991: A study of the formation, circulation and ventilation of eastern North Atlantic Central Water, Prog. Oceanogr., 37, 167-172, doi:10.1016/S0079-6611(96)00008-0.

Poole, R., and M. Tomczak (1999), Optimum multiparameter analysis of the water mass structure in the Atlantic Ocean thermocline, Deep Sea Res. Part I, 46, 1895-1921, doi:10.1016/S0967-0637(99)00025-4.

Reverdin, G., M. Assenbaum, and L. Prieur (2005), Eastern North Atlantic mode waters during POMME (September 2000-2001), J. Geophys. Res. 110, C07S04, doi:10.1029/2004JC002613.

Rios, A. F., F. F. Perez, and F. Fraga (1992), Water Masses in the upper and middle North Atlantic Ocean east of the Azores, Deep Sea Res., 39, 645-658, doi:10.1016/0198-0149(92)90093-9.

Saunders, P. M. (1982), Circulation in the eastern North Atlantic, J. Mar. Res., 40, 641-657.

Siedler, G., L. Armi, and T. J. Muller (2005), Meddies and decadal changes at the Azores Front from 1980 to 2000, Deep Sea Res. Part II, 52, 583604, doi:10.1016/j.dsr2.2004.12.010.

Speer, K. G., J. Gould, and J. LaCasce (1999), Year-long float trajectories in the Labrador Sea Water of the eastern North Atlantic Ocean, Deep Sea Res. Part II, 46, 165-179, doi:10.1016/S0967-0645(98)00103-9.

Sy, A. (1988), Investigation of Large-scale circulation patterns in the central North Atlantic: The North Atlantic current, the Azores current, and the Mediterranean Water plume in the area of the Mid-Atlantic Ridge, Deep Sea Res., 35, 383-413, doi:10.1016/0198-0149(88)90017-9.

Zenk, W., and L. Armi (1990), The complex spreading pattern of Mediterranean Water off the Portuguese continental slope, Deep Sea Res., 37 1805-1823, doi:10.1016/0198-0149(90)90079-B.

M. Álvarez, Instituto Mediterráneo de Estudios Avanzados, CSIC, Universitat de les Illes Balears, Miquel Marqués 21, Esporles E-07190, Spain.

L. Barbero, LOCEAN, IPSL, Pierre and Marie Curie University, F-75252 Paris CEDEX 5, France.

M. González-Dávila and J. M. Santana-Casiano, Chemistry Department, University of Las Palmas de Gran Canaria, E-35017 Las Palmas de Gran Canaria, Spain. (mgonzalez@dqui.ulpgc.es) 